\title{
Eficácia da suplementação oral com 1,3-1,6 betaglucano proveniente de Saccharomyces cerevisiae no controle da mastite bovina
}

[Efficiency of oral supplementation of 1.3-1.6 beta-glucan from saccharomyces cerevisiae on the control of bovine mastitis ]

\author{
G.C. Gimenes ${ }^{1}$, E.H. Dias $^{2}$, S.H.F. Dias $^{3}$, G.L. Bastos ${ }^{3}$, A.R. Gerbasi ${ }^{3}$, \\ A.F.B. Almada' ${ }^{2}$ J.L. Borges ${ }^{2}$, D.D. Gonçalves ${ }^{2}$, \\ J.V.M. Simões ${ }^{3}$, R. Piau Júnior ${ }^{* 2}$ \\ ${ }^{1}$ Ágora Clínica Veterinária- Umuarama, PR \\ ${ }^{2}$ Programa de pós-graduação - Universidade Paranaense - Unipar - Umuarama, PR \\ ${ }^{3}$ Universidade Paranaense - Unipar - Umuarama, PR
}

\begin{abstract}
RESUMO
A mastite bovina, uma das principais doenças do rebanho leiteiro, caracteriza-se por um processo inflamatório no úbere. A inviabilidade econômica, o impacto ambiental negativo e os resíduos antimicrobianos têm estimulado a pesquisa de outros tratamentos alternativos para a prevenção e o tratamento de doenças na bovinocultura leiteira. O betaglucano é um agente imunomodulador com potencial ação preventiva para doenças infecciosas, inclusive a mastite. Este estudo teve como objetivo avaliar a eficácia do uso do betaglucano, por meio de administração oral, em animais em lactação. Foram utilizadas 20 vacas lactantes, distribuídas em dois grupos, um controle e um tratamento, com 10 animais em cada grupo. O grupo tratamento recebeu 5g/dia, durante 60 dias, de 1,3-1,6 betaglucano isolado da parede celular de Saccharomyces cerevisiae diluído em ração após a ordenha, enquanto o grupo controle recebia somente a ração. Foram realizados os testes de California Mastitis Test (CMT), contagem de células somáticas (CCS), produção de leite e percentual de gordura e proteína no leite. Não houve diferença estatisticamente significativa entre os grupos quanto à CCS, ao CMT, à composição do leite ou produção. Não se observou, portanto, eficácia do uso do betaglucano purificado, administrado por via oral, no controle e na prevenção da mastite em vacas leiteiras, quando comparadas com o grupo controle. Atribuem-se esses resultados, principalmente, à degradação ruminal do produto testado. Sugerem-se, portanto, mais pesquisas utilizando o 1,3-1,6 betaglucano purificado de parede de $S$. cerevisiae por outras vias de administração, tais como intramamária e subcutânea.
\end{abstract}

Palavras-chave: betaglucano, bovinos, imunomodulador, mastite, prebiótico

\begin{abstract}
Bovine mastitis, one of the main diseases of dairy herds, is characterized by an inflammatory process in the udder. The economic and environmental impacts, as well as the residues of antimicrobial drugs have stimulated the research of novel alternative treatments for the prevention and treatment of diseases in dairy production cows. The beta-glucan is an immunomodulator agent, with potential preventive action for infectious diseases, including mastitis. This study aimed to assess the effectiveness of orally administered beta-glucan in lactating cows. 20 lactating cows were used, distributed into two groups, one control and one treatment, with $10 \mathrm{cows}$ in each group. The treatment group received $5 \mathrm{~g}$ of 1.3-1.6 betaglucan daily for 60 days, isolated from the cell-wall of Saccharomyces cerevisiae diluted into a grain meal, whereas the animals in the control group received only the ration. The California Mastitis Test (CMT), Somatic Cells Counting (SCC), daily production and assessments of fat and protein content in milk were done. There was no statistically significant difference between the groups concerning subclinical mastitis detected by CMT, $S C C$, milk production and composition regarding protein and fat content. It was not observed, therefore,
\end{abstract}

Recebido em 7 de junho de 2018

Aceito em 5 de março de 2020

*Autor para correspondência (corresponding author)

E-mail: piau@prof.unipar.br 
the effectiveness of the use of purified beta-glucan orally administered on the control or prevention of mastitis in dairy cows. The results are attributed to the ruminal degradation of the product tested. It is, therefore, suggested that more research should be conducted using the 1.3-1.6 beta-glucan purified from the cell wall of S. cerevisiae by other administration means and ruminal protection technologies for the isolated beta-glucan.

Keywords: betaglucan, bovine, immunemodulator, mastitis, prebiotic

\section{INTRODUÇÃO}

A mastite bovina constitui o problema sanitário mais abrangente e mais oneroso à atividade leiteira no país. Caracteriza-se pela inflamação da glândula mamária, podendo ser classificada como clínica e subclínica, sendo a forma subclínica muito mais frequente e um indicativo de sanidade do rebanho (Blood e Radostits, 1991; Muller, 2002). As mastites podem ser causadas por bactérias (Beloti et al., 1997), fungos (Spanamberg et al., 2009) ou por algas (Bueno et al., 2006), e os agentes mais comuns são as bactérias dos gêneros Staphylococcus e Streptococcus (Fonseca e Santos, 2000). O diagnóstico da mastite subclínica é comumente feito por meio do California Mastitis Test (CMT) e da contagem de células somáticas (CCS) (Fonseca e Santos, 2000).

O tratamento da mastite é normalmente realizado mediante o uso de antibióticos e agentes antifúngicos, por meio de administração sistêmica ou intramamária. Entretanto, a taxa de cura para mastite tem se tornado bastante variável, provavelmente devido à formação de biofilme e à resistência microbiana induzida pelo uso de antimicrobianos por tempo prolongado (Spanamberg et al., 2009; Tiwari et al., 2013).

Diversas alternativas ao tratamento com antimicrobianos têm sido estudadas (Crispie $e t$ al., 2008; Gangwar et al., 2008; Tiwari et al., 2013). Dentre essas alternativas, destacam-se os imunomoduladores, agentes capazes de estimular o sistema imune do animal, tornando-o mais apto a resistir e a combater infecções. Esse processo se dá por meio da ativação de mecanismos celulares e de complemento (Falcon, 2007). Muitos desses produtos são prebióticos que podem ser usados na forma de aditivos nutricionais, pela facilidade de administração e pela redução do custo de produção (Silva e Nörnberg, 2003; Bandeira et al., 2007; Mendes et al., 2010).
Entre os imunomoduladores, os glucanos têm demonstrado potencial de eficácia em várias espécies. Glucanos são substâncias compostas de moléculas de glicose arranjadas em uma configuração espacial específica, que podem ter origem vegetal ou microbiana, contendo moléculas de 1,3 e 1,6 betaglucano (Robertsen et al., 1994; Sakai, 1999; Gannam e Schrock, 2001). O betaglucano é encontrado em concentrações de 2 a $6 \%$ em cereais como a aveia e a cevada, sendo esses uma das fontes de betaglucanos para imunomodulação (Genç et al., 2001). Entretanto, encontram-se os glucanos funcionais em proporções bastante maiores em microrganismos, de forma especial em leveduras. A parede celular da levedura contém cerca de $40 \%$ de betaglucano (Hough, 1990).

As leveduras são usadas em processos industriais de fermentação, com destaque para a fermentação da cana-de-açúcar para fabricação de etanol. A espécie comumente usada no processo fermentativo consiste de Saccharomyces cerevisiae (Costa, 2004). A partir da biomassa de S. cerevisiae, pode-se obter o betaglucano purificado, mediante o fracionamento dos componentes da parede celular do microrganismo. A purificação do agente específico contribui para a eficácia imunomoduladora e reduz a indução de inflamação por meio do uso de compostos mais puros. Estudos têm demonstrado a capacidade do betaglucano isolado em ativar e estimular a resistência imunológica em diversas espécies (Brown e Gordon, 2003; Li et al., 2005).

Entre os efeitos do betaglucano, incluem-se a melhora nas imunidades inespecífica e específica, a redução no risco de doenças por infecções oportunistas, a redução na mortalidade por infecções patogênicas, a melhora na resistência a parasitas, o aumento na eficácia das vacinas e dos antibióticos (efeito adjuvante), agindo em sinergia com as vitaminas C, E e o selênio (Volman et al., 2008). Os betaglucanos, ao modularem a resposta 
imunológica, preparam melhor os animais aos desafios sanitários (Mendes et al., 2010).

O objetivo do presente estudo foi avaliar a eficácia da suplementação oral com 1,3-1,6 betaglucano isolado da parece celular de Saccharomyces cerevisiae, no controle e na prevenção da mastite bovina, em vacas leiteiras em sistema de produção intensivo a pasto.

\section{MATERIAL E MÉTODOS}

O experimento foi aprovado pelo Comitê de Ética em Pesquisa Envolvendo Experimentação Animal da Universidade Paranaense, sob o protocolo $\mathrm{n}^{\circ}$ 22166. Foram utilizados 20 bovinos leiteiros, Bos taurus taurus, de raça Holandesa, em lactação, em sistema de produção intensivo a pasto (Assis et $a l ., 2005$ ), provenientes do setor de bovinocultura de leite da Universidade Paranaense. Os animais foram mantidos em sua rotina costumeira, sem alteração de horários, dieta ou locais de pastejo e ordenha.

A ordenha foi realizada duas vezes ao dia, de manhã e à tarde, respeitando-se os princípios de boas práticas de ordenha (Rosa et al., 2009). Na ordenha vespertina, foi realizada a intervenção experimental mediante acompanhamento de médico veterinário, buscando o mínimo distúrbio à rotina habitual, evitando-se, assim, indução de estresse. Foram selecionados 20 animais, distribuídos em dois grupos com 10 animais cada, sendo um grupo tratado com betaglucano e outro sendo grupo controle. Os animais selecionados permaneceram em lactação durante todo o período do experimento e consistiam de vacas multíparas livres de mastite clínica e que não eram tratadas com qualquer medicamento.

Foi realizado exame de CMT anteriormente ao início do experimento. Foram selecionados animais livres e portadores de mastite subclínica (considerando-se reação de qualquer grau como determinante de presença da mastite subclínica). Foram, então, determinados quatro grupos de cinco animais cada, sendo: um grupo controle composto de animais positivos para mastite subclínica; um grupo controle composto de animais negativos para mastite subclínica; um grupo tratamento (betaglucano) composto de animais positivos para mastite subclínica; um grupo tratamento (betaglucano) composto de animais negativos para mastite subclínica.
Aos animais dos grupos tratamento foi fornecido betaglucano (moléculas de 1,3 e 1,6 betaglucano), obtido por meio da purificação e do fracionamento da parede celular de Saccharomyces cerevisiae, na dosagem de $5 \mathrm{~g} /$ animal/dia, conforme recomendação do fabricante, administrado junto com a ração, após a ordenha. O betaglucano foi oferecido em pó, misturado a aproximadamente $300 \mathrm{~g}$ de ração e $5 \mathrm{~g}$ de melaço de cana em pó, adicionado para aumentar a palatabilidade. Os animais dos grupos controle recebiam a mesma quantidade de ração e melaço, excluindo-se somente o produto em teste. Em um período de 30 dias, anterior ao início da administração do betaglucano, as vacas de todos os grupos receberam apenas ração na mesma quantidade do experimento, a fim de que fossem adaptadas à rotina.

O leite dos animais foi submetido ao California Mastitis Test (CMT) para estimar a presença e o grau de mastite subclínica. O teste foi realizado com placa de teste e reagente de bromocresol. Considerou-se positivo qualquer teste que apresentasse gelificação, conforme determina o fabricante do reagente. As amostras para CCS foram acondicionadas em frascos de polietileno, com tampa de rosca e capacidade de $50 \mathrm{~mL}$, contendo duas pastilhas do conservante bronopol (2-bromo-2-nitropropano-1,3-diol), etiquetadas e encaminhadas para o Laboratório do Programa de Análise de Leite da Associação Paranaense de Criadores de Bovinos da Raça Holandesa (APCBRH), em Curitiba, estado do Paraná, utilizando-se o aparelho Somacount 500 (Bentley Instruments ${ }^{\circledR}$ ).

A composição do leite foi avaliada no dia inicial e nos dias 30 e 60, sendo a amostra utilizada para composição a mesma usada para análise da CCS. Foi analisado o teor percentual de gordura e proteína do leite dos animais tratados com betaglucano e dos grupos controle. Os dados foram analisados no programa Bioestat 5.3, utilizando-se ANOVA fatorial para os dados de CCS e composição do leite, sendo a análise realizada entre os animais de um mesmo grupo e entre os grupos. Para os dados de CMT, foi realizado o teste exato de Fischer. Foi utilizado nível de significância de 5\% (Ayres et al., 2007). 


\section{RESULTADOS E DISCUSSÃO}

Na Tab. 1, são apresentados os resultados do teste do California Mastitis Test (CMT) nos animais tratados com betaglucano e nos animais do grupo controle. Não foram observadas diferenças estatisticamente significativas $(\mathrm{P}>0,05)$ entre os grupos em nenhum dos tempos avaliados.

Tabela 1. Resultados do California Mastitis Test (CMT) dos animais submetidos aos diferentes tratamentos

\begin{tabular}{|c|c|c|c|}
\hline \multirow[b]{2}{*}{ Tempo (dias) } & \multirow[b]{2}{*}{ Grupos } & \multicolumn{2}{|c|}{ CMT } \\
\hline & & Positivo & Negativo \\
\hline \multirow[t]{2}{*}{ Inícial } & Betaglucano & 07 & 33 \\
\hline & Controle & 07 & 33 \\
\hline \multirow[t]{2}{*}{ D30 } & Betaglucano & 05 & 35 \\
\hline & Controle & 06 & 34 \\
\hline \multirow[t]{2}{*}{ D60 } & Betaglucano & 16 & 24 \\
\hline & Controle & 12 & 28 \\
\hline
\end{tabular}

CMT negativo (sem reação), CMT positivo (escores + ou ++ ou +++).

O teste de CMT apresenta grande relevância prática na pesquisa e na prevenção da mastite, uma vez que é o método usado com maior frequência para acompanhamento e avaliação de rebanhos leiteiros (Dias, 2007). A literatura é escassa em estudos que correlacionam o uso de imunomoduladores e a incidência de mastite, mas, conforme Naresh et al. (2002), a eficácia do uso de imunomoduladores, como o ácido ascórbico, como aditivos orais adicionados à dieta de vacas lactantes pode ser avaliada por meio do teste de CMT. O betaglucano possui ação imunomoduladora, que estimula órgãos linfoides primários e secundários, potencializa a atividade de macrófagos e contribui para a resistência a infecções (Saleh et al., 2015). No presente trabalho, não se observou alteração significativa no escore do CMT no leite dos animais, quando de compararam os grupos tratados e não tratados com betaglucano.
Os resultados da contagem de células somáticas estão apresentados na Tab. 2. Não se observaram diferenças significativas entre os grupos ou entre os tempos avaliados. Esse resultado contrasta com outros estudos do uso de betaglucanos em ruminantes, tais como os estudos de Buddle et al. (1988), Estrada et al. (1999), Waller e Colditz (1999), Persson Waller et al. (2003) e de Graves e Ward (2010). Os resultados desses estudos, entretanto, divergem daqueles obtidos no presente trabalho no tocante ao delineamento experimental. Apesar de demonstrarem a eficácia do 1,3 e 1,6 betaglucano como imunomodulador em ruminantes, apenas Graves e Ward (2010) utilizaram administração oral do betaglucano, mas usaram bezerros de zero a oito semanas e avaliaram a incidência de outros tipos de infecções.

Tabela 2. Contagem de células somáticas (CCS) x $10^{3}$ por $\mathrm{mL}$ de leite de vacas submetidas aos diferentes tratamentos

\begin{tabular}{|c|c|c|c|}
\hline Tempo (dias) & & & $\mathrm{CCSx} 10^{3} / \mathrm{mL}$ \\
\hline \multirow{4}{*}{ Início } & \multirow{2}{*}{ Betaglucano } & $\mathrm{CMT}^{+}$ & $583,20 \pm 192,58$ \\
\hline & & $\mathrm{CMT}^{-}$ & $112,40 \pm 47,41$ \\
\hline & \multirow{2}{*}{ Controle } & $\mathrm{CMT}^{+}$ & $599,60 \pm 156,36$ \\
\hline & & $\mathrm{CMT}^{-}$ & $231,60 \pm 48,02$ \\
\hline \multirow{4}{*}{ D30 } & \multirow{2}{*}{ Betaglucano } & $\mathrm{CMT}^{+}$ & $776,20 \pm 227,20$ \\
\hline & & $\mathrm{CMT}^{-}$ & $193,60 \pm 39,01$ \\
\hline & \multirow{2}{*}{ Controle } & $\mathrm{CMT}^{+}$ & $754,40 \pm 329,05$ \\
\hline & & $\mathrm{CMT}^{-}$ & $207,60 \pm 74,84$ \\
\hline \multirow{4}{*}{ D60 } & \multirow{2}{*}{ Betaglucano } & $\mathrm{CMT}^{+}$ & $638,60 \pm 320,20$ \\
\hline & & $\mathrm{CMT}^{-}$ & $286,00 \pm 143,67$ \\
\hline & \multirow{2}{*}{ Controle } & $\mathrm{CMT}^{+}$ & $315,40 \pm 190,19$ \\
\hline & & $\mathrm{CMT}^{-}$ & $128,40 \pm 49,56$ \\
\hline
\end{tabular}

CMT negativo (sem reação), CMT positivo (escores + ou ++ ou +++). Valores médios + DP. 
Buddle et al. (1988) e Estrada et al. (1999) estudaram a influência do betaglucano sobre infecções em ruminantes, realizando-se a aplicação do betaglucano por via subcutânea, tendo que Estrada et al. (1999) obtido resultados somente em animais imunossuprimidos por corticosteroides. Waller e Colditz (1999) e Persson Waller et al. (2003) alcançaram resultados positivos com o uso do betaglucano em preparação intramamária, mas, no estudo, os autores não obtiveram resultados curativos e, sim, preventivos, condizentes com o mecanismo de ação dos imunomoduladores.

Os resultados obtidos no presente estudo são semelhantes aos de Uchiyama et al. (2012), que verificaram que a suplementação oral com 1,3-1,6 betaglucano purificado, proveniente de fungos Aureobasidium pullulans, não alterou de forma significativa o CCS de vacas em lactação, mas alterou moderadamente a expressão de citocinas séricas.

$\mathrm{Na}$ Tab. 3, estão apresentados os resultados da produção de leite, da porcentagem de gordura e da porcentagem de proteína no leite de vacas leiteiras tratadas com o betaglucano e dos grupos controle. Não se identificaram diferenças significativas entre os grupos ou entre os tempos avaliados $(\mathrm{P}>0,05)$ para os resultados referentes à produção diária de leite e à porcentagem de gordura e proteína das amostras de leite dos animais submetidos aos diferentes tratamentos.

Tabela 3. Produção de leite $(\mathrm{kg} / \mathrm{dia})$, concentração $(\%)$ de gordura e proteína do leite obtido de vacas submetidas aos diferentes tratamentos

\begin{tabular}{|c|c|c|c|c|c|}
\hline Tempo (dias) & Gru & & Produção kg & $\%$ Gordura & \% Proteína \\
\hline \multirow{4}{*}{ Inicial } & \multirow[t]{2}{*}{ Betaglucano } & $\mathrm{CMT}^{+}$ & $17,60 \pm 1,80$ & $3,88 \pm 0,17$ & $3,44 \pm 0,20$ \\
\hline & & $\mathrm{CMT}^{-}$ & $13,80 \pm 0,37$ & $4,00 \pm 0,17$ & $3,69 \pm 0,09$ \\
\hline & \multirow{2}{*}{ Controle } & $\mathrm{CMT}^{+}$ & $14,20 \pm 1,59$ & $3,78 \pm 0,12$ & $3,50 \pm 0,12$ \\
\hline & & $\mathrm{CMT}^{-}$ & $18,60 \pm 3,04$ & $4,03 \pm 0,15$ & $3,39 \pm 0,14$ \\
\hline \multirow{4}{*}{ D30 } & \multirow[t]{2}{*}{ Betaglucano } & $\mathrm{CMT}^{+}$ & $17,00 \pm 2,07$ & $3,83 \pm 0,20$ & $3,48 \pm 0,18$ \\
\hline & & $\mathrm{CMT}^{-}$ & $14,40 \pm 0,40$ & $4,05 \pm 0,18$ & $3,79 \pm 0,12$ \\
\hline & \multirow[t]{2}{*}{ Controle } & $\mathrm{CMT}^{+}$ & $13,40 \pm 1,36$ & $3,90 \pm 0,20$ & $3,71 \pm 0,05$ \\
\hline & & $\mathrm{CMT}^{-}$ & $18,00 \pm 2,86$ & $3,72 \pm 0,12$ & $3,35 \pm 0,11$ \\
\hline \multirow{4}{*}{ D60 } & \multirow[t]{2}{*}{ Betaglucano } & $\mathrm{CMT}^{+}$ & $17,40 \pm 4,39$ & $4,15 \pm 0,23$ & $3,59 \pm 0,17$ \\
\hline & & $\mathrm{CMT}^{-}$ & $15,80 \pm 1,39$ & $4,11 \pm 0,30$ & $3,72 \pm 0,18$ \\
\hline & \multirow[t]{2}{*}{ Controle } & $\mathrm{CMT}^{+}$ & $12,20 \pm 2,06$ & $3,86 \pm 0,15$ & $3,69 \pm 0,07$ \\
\hline & & $\mathrm{CMT}^{-}$ & $18,80 \pm 2,48$ & $3,66 \pm 0,30$ & $3,47 \pm 0,14$ \\
\hline
\end{tabular}

CMT negativo (sem reação), CMT positivo (escores + ou ++ ou +++), valores médios \pm erro-padrão.

Não houve influência do tratamento com o betaglucano na composição do leite produzido (Tab. 3), diferentemente dos resultados obtidos por Uchiyama et al. (2012). Silva et al. (2018), ao utilizarem betaglucano solúvel por via intramamária, observaram um aumento significativo nas porcentagens de gordura, proteína, lactose e sólidos totais no leite dos animais tratados. No presente estudo, não houve diferenças significativas nas porcentagens de gordura e proteínas do leite. Entretanto, o betaglucano foi administrado em outra via de administração; o produto foi oferecido na dieta dos animais.

A ausência de resultados significativos nas variáveis estudadas provavelmente se deve à forma de administração do betaglucano. A viabilidade e a simplicidade da administração oral do produto justificam essa via como a primeira opção para avaliação da hipótese. Os betaglucanos são polissacarídeos e, como tais, compostos de açúcares, portanto podem ser digeríveis pela vasta microbiota ruminal.

A literatura é extensa em evidência de estímulo imune por meio da administração oral de betaglucanos em monogástricos (Chen et al., 2003; Guo et al., 2003; Lowry et al., 2005; Chae et al., 2006; Palić et al., 2006; Zhang et al., 2008). Entretanto, deve-se levar em conta que a digestão de monogástricos é bastante diferente da digestão de ruminantes, com os quais estudos envolvendo betaglucanos são escassos, quanto mais se considerado o uso de formas isoladas $\mathrm{e}$ purificadas do produto (Estrada et al., 1999). 
Grove et al. (2006) demonstraram a digestibilidade ruminal do betaglucano isolado em bovinos como sendo superior a $85 \%$, o que ainda permite a passagem de parte do produto para o intestino, onde ele é ativo, mas há perda de grande parte do produto administrado como fonte de energia para os microrganismos ruminais.

Esse processo de degradação ruminal dos betaglucanos é possivelmente evitado por meio da proteção do polissacarídeo com compostos menos digeríveis. Grove et al. (2006) obtiveram 54\% de proteção ruminal ao betaglucano originário da aveia em uma das variedades de aveia estudadas. Essa proteção foi conferida pela fibra de menor digestibilidade presente na variedade menos degradada, o que abre a possibilidade do desenvolvimento de formas de proteção do betaglucano proveniente de $S$. cerevisiae.

O ácido tânico apresenta possível capacidade protetiva para amidos no rúmen, quando adicionado a alimento pulverizado rico em amido (Martinez et al., 2005), podendo exercer efeito semelhante sobre o betaglucano, que também é um polímero de glicose. Outra alternativa de proteção ruminal seria a utilização de encapsulamento $\mathrm{pH}$-dependente, para garantir a passagem do betaglucano pelo ambiente ruminal, conforme sugerem Cao et al. (2008), com grande potencial de eficácia, porém com custo provavelmente elevado.

Uma opção para se utilizarem os efeitos imunoestimulantes dos betaglucanos é a aplicação subcutânea. O produto empregado no presente estudo possui alto grau de pureza. Ao ser-lhe avaliada a esterilidade, foi possível preparar uma solução para administração subcutânea, semelhante ao método utilizado por Buddle et al. (1988) e Estrada et al. (1999), que obtiveram resultados positivos na estimulação do sistema imune em ruminantes tratados com betaglucano de outras fontes.

Alternativamente à administração oral, pode-se, também, realizar a preparação de pomadas intramamárias contendo 1,3-1,6 betaglucano para utilização preventiva e associada a tratamentos tradicionais, conforme o já descrito por Waller e Colditz (1999), com resultados positivos em ovelhas, em que se obteve maior ativação de macrófagos no ambiente da glândula mamária durante o período seco e pôde-se conferir menor incidência de mastite durante a lactação. Persson Waller et al. (2003) utilizaram infuso intramamário com betaglucano em vacas e obtiveram efeito preventivo, entretanto o número de animais testados não foi suficiente para estabelecer a eficácia da técnica. $O$ teste intramamário com o 1,3-1,6 betaglucano purificado a partir de $S$. cerevisiae possui grande relevância, uma vez que o produto testado no presente estudo tem alto nível de pureza, além de haver indícios bastante sólidos para que essa abordagem, de custo geralmente acessível e administração amigável à rotina de ordenha, forneça efeitos preventivos e até mesmo auxilie no tratamento das mastites.

\section{CONCLUSÕES}

A suplementação oral com 1,3-1,6 betaglucano purificado a partir de $S$. cerevisiae, na dose de $5 \mathrm{~g} /$ animal/dia, nas condições experimentais avaliadas, não reduziu a incidência de mastite subclínica avaliada por teste de CMT e não produziu alterações significativas nos valores de CCS, teor de gordura ou proteína do leite das vacas tratadas quando comparadas com o grupo controle. A ineficácia do tratamento provavelmente se deve à forma de administração, sendo sugerido, portanto, o estudo de formas alternativas de administrar o produto.

\section{AGRADECIMENTOS}

Os autores deste trabalho agradecem à Universidade Paranaense (Unipar), pelo fornecimento dos meios para realização da pesquisa, incluindo suporte financeiro por meio do Programa Institucional de Bolsas.

\section{REFERÊNCIAS}

ASSIS, A.G.; STOCK, L.A.; CAMPOS, O.F. et al. Sistemas de produção de leite no Brasil. Juiz de Fora, MG: Embrapa Gado de Leite, 2005. 6p. (Circular Técnica, n.85)

AYRES, M.; AYRES, J. R.M.; AYRES, D.L. et al. BioEstat 5.0: aplicações estatísticas nas áreas das Ciências Bio-Médicas. Belém-PA: Sociedade Civil Mamirauá, MCT-CNPq, 2007. 364p.

BANDEIRA, C.M.; FONTES, D.O.; SOUZA, L.P.O. et al. Saúde intestinal dos leitões: um conceito novo e abrangente. Cad. Téc.Vet. Zootec., v.54, p.1-97, 2007. 
BELOTI, V.; MULLER, E.E.; FREITAS, J.C. et al. Estudo da mastite subclínica em rebanhos leiteiros no norte do Paraná. Semin. Ciênc. Agrár., v.18, p.45-53, 1997.

BLOOD, D.C.; RADOSTITS, O.M. Clínica veterinária. 7.ed. Rio de Janeiro: Guanabara Koogan, 1991. 1561p.

BROWN G.D.; GORDON S. Fungal $\beta$-glucans and mammalian immunity. Immunity, v.19, p.311-315, 2003.

BUDDLE, B.M.; PULFORD, H.D.; RALSTON, M. Protective effect of glucan against experimentally induced staphylococcal mastitis in ewes. Vet. Microbiol., v.16, p.67-76, 1988.

BUENO, V.F.F.; MESQUITA, A.J.; DIAS FILHO, F.C. Prototheca zopfii: importante patógeno na etiologia da mastite bovina no Brasil. Ciênc. Anim. Bras., v.7, p.273-283, 2006.

CAO, Q.R.; LEE, E.S.; CHOI, Y.J. et al. Rumen bypass and biodistribution of 1-carnitine from dual-layered coated pellets in cows, in vitro and in vivo. Int. J. Pharmacol., v.359, p.87-93, 2008.

CHAE, B.J.; LOHAKARE, J.D.; MOON, W.K. et al. Effects of supplementation of $\beta$-glucan on the growth performance and immunity in broilers. Res. Vet. Sci., v.80, p.291-298, 2006.

CHEN, H.; LI, D.; CHANG, B.; GONG, L. et al. Effects of lentinan on broiler splenocyte proliferation, interleukin-2 production, and signal transduction. Poult. Sci., v.82, p.760-766, 2003.

COSTA, L.F. Leveduras na nutrição animal. Rev. Eletr. Nutritime, v.1, p.1-6, 2004. Disponível em: <http://www.nutritime.com.br/arquivos_internos/ artigos/001V1N1P01_06_JUL2004.pdf>.

Acessado em: 05 abr. 2018.

CRISPIE, F.; GOMEZ, M.A.; O'LOUGHLIN, C. et al. Intramammary infusion of a live culture for treatment of bovine mastitis: effect of live lactococci on the mammary immune response. $J$. Dairy Res., v.75, p.374-384, 2008.

DIAS, R.V.C. Principais métodos de diagnósticos e controle da mastite bovina. Acta Vet. Bras., v.1, p.23-27, 2007.

ESTRADA, A.; KESSEL, A.; LAAVELD, B. Effect of administration of oat $\beta$-Glucan on immune parameters of healthy and immunosuppressed beef steers. Can. J. Vet. Res., v.63, p.261-268, 1999.
FALCON, D.R. Beta Glucano e vitamina $C$ no desempenho produtivo e parâmetros fisiopatológicos em juvenis de tilápia-do-Nilo: nível de suplementação e tempo de administração. 2007. 158f. Tese (Doutorado em Aquicultura) Universidade Estadual Paulista, Jabuticabal, SP.

FONSECA, L.F.L.; SANTOS, M.V. Qualidade do leite e controle de mastite. São Paulo: Lemos, 2000.175 p.

GANGWAR, P.; UPADHYAY, A.K.; GANGWAR, N.K. et al. Relationship of mineral and vitamin supplementation with mastitis. Vet. World, v.1, p.103-104, 2008.

GANNAM, A.L.; SCHROCK, R.M. Immunostimulants in fish diets. In: LIM C.; WEBSTER, C.D. Nutrition and fish health. New York: Haworth Press, 2001. p.235-260,

GENÇ, H.; OZDEMIR, M.; DEMIRBAS, A. Analysis of mixed-linked (1-3), (1-4)- $\beta$-Dglucans in cereals grains from Turkey. Food Chem., v.73, p.221-224, 2001.

GRAVES, J.M.; WARD, S.H. Performance of Holstein heifers supplemented with Coccidiostat, Mannanoligosaccharide, or $\beta$ glucan. Mississippi State Univ. Anim. Dairy Sci. Dep. Rep., p.53-61, 2010. Available in: $<$ http://www.ads.msstate.edu/docs/annual_report /annualreport2010.pdf >. Accessed in: 16 Sep. 2017.

GROVE, A.V.; KAISER, C.R.; IVERSEN, N. et al. Digestibility of barley beta-glucan in cattle. In: WESTERN SECTION AMERICAN SOCIETY OF ANIMAL SCIENCE, 57., 2006, Logan. Proceedings... Logan: WSASAS, 2006. p.367396 ,

GUO, Y.; ALI, R.A.; QURESHI, M.A. The influence of $\beta$-glucan on immune responses in broiler chicks. Immunopharmacol. Immunotoxicol., v.25, p.461-472, 2003.

HOUGH, J.S. Biotecnología de la cerveza y de malta. Zaragoza: Acribia, 1990. 194p.

LI, J.; XING, J.; LI, D. et al. Effects of $\beta$-glucan extracted from Saccharomyces cerevisiae on humoral and cellular immunity in weaned piglets. Arch. Anim. Nutr., v.59, p.303-312, 2005. 
LOWRY, V.K.; FARNELL, M.B.; FERRO, P.J. et al. Purified $\beta$-glucan as an abiotic feed additive up-regulates the innate immune response in immature chickens against Salmonella enterica serovar Enteritidis. Int. J. Food Microbiol., v.98, p.309-318, 2005.

MARTÍNEZ, T.F.; MOYANO, F.J.; DIAZ, M. et al. Use of tannic acid to protect barley meal against ruminal degradation. J. Sci. Food. Agric., v.85, p.1371-1378, 2005.

MENDES, C.B.S.; FONTES, D.O.; GUEDES, R.M.C. et al. Suplementação de betaglucano a dietas de leitões de 21 a 60 dias de idade. Arq. Bras. Med. Vet. Zootec., v.62, p.696-705, 2010.

MULLER, E.E. Qualidade do leite, células somáticas e prevenção da mastite. In: SIMPÓSIO SOBRE SUSTENTABILIDADE DA PECUÁRIA LEITEIRA NA REGIÃO SUL DO BRASIL, 2., 2002, Maringá. Anais... Maringá: NUPEL, 2002. p.206-217.

NARESH, R.; DWIVEDI, S.K.; SWARUP, D.; PATRA, R.C. Evaluation of ascorbic acid treatment in clinical and subclinical mastitis of Indian dairy cows. Assian Australas. J. Anim. Sci., v.15, p.905-911, 2002.

PALIĆ, D.; ANDREASEN, C.B.; HEROLT, D.M. et al. Immunomodulatory effects of $\beta$ glucan on neutrophil function in fathead minnows (pimephales promelas rafinesque, 1820). Dev. Comp. Immunol., v.30, p.817-830, 2006.

PERSSON WALLER, K.P.; GRÖNLUND, U.; JOHANNISSON, A. Intramammary infusion of $\beta$ 1, 3-glucan for prevention and treatment of Staphylococcus aureus mastitis. J. Vet. Med., v.50, p.121-127, 2003.

ROBERTSEN, B.; ENGSTAD, R.E.; JORGENSEN, J.B. 6-Glucans as immunostimulants. In: J. STOLEN, T.C. FLETCHER, F. H. Modulators of fish immune responses. Lagos, Nigeria: SOS Publication, 1994. v.1, p.83-99.

ROSA, M.S.; COSTA, M.J.R.P.; SANT'ANNA, A.C. Boas prática de manejo - ordenha. Jaboticabal: FUNEP, 2009. 43p.
SAKAI, M. Current research status of fish immunostimulants. Aquaculture, v.172, p.63-92, 1999.

SALEH, M.A.; AMORIM, A.B.; GRECCO, H.A. et al. Effects of $\beta-(1 \rightarrow 3,1 \rightarrow 6)$-d-glucan and density of diets on the blood profiles of immunologically challenged weaned piglets. Intern. J. Biol. Macromol., v.80, p.659-667, 2015.

SILVA, L.P.; NÖRNBERG, J.L. Prebióticos na nutrição de não ruminantes. Ciênc. Rural, v.33, p.983-990, 2003.

SILVA, V.S.; PIAU JUNIOR, R.; BORGES, J.L. et al. Beta-glucano solúvel intramamário no controle de mastites subclinicas. Encicl. Biosfera, v.15, p.194-200, 2018.

SPANAMBERG, A.; SANCHES, E.M.C.; SANTURIO, J.M. et al. Mastite micótica em ruminantes causada por leveduras. Ciênc. Rural, v.39, p.282-290, 2009.

TIWARI, J.G.; BABRA, C.; TIWARI, H.K. et al. Trends in therapeutic and prevention strategies for management of bovine mastitis: an overview. $J$. Vaccines Vaccinations, v.4, p.1-11, 2013.

UCHIYAMA, H.; IWAI, A.; ASADA, Y. et al. A small scale study on the effects of oral administration of the $\beta$-glucan produced by Aureobasidium pullulans on milk quality and cytokine expressions of Holstein cows, and on bacterial flora in the intestines of Japanese black calves. BMC Res. Notes, v.5, p.189, 2012.

VOLMAN, J.J.; RAMAKERS, J.D.; PLAT, J. Dietary modulation of immune function by $\beta$ glucans. Physiol. Behav., v.94, p.276-284, 2008

WALLER, K.P.; COLDITZ, I.G. Effect of intramammary infusion of beta-1,3-glucan or interleukin-2 on leukocyte subpopulations in mammary glands of sheep. Am. J. Vet. Res., v.60, p.703-707, 1999.

ZHANG, B.; GUO, Y.; WANG, Z. The modulating effect of 1,3/1,6-glucan supplementation in the diet on performance and immunological responses of broiler chickens. Asian Australas. J. Anim. Sci., v.21, p.237-244, 2008. 